\title{
$1 \mathrm{GPa}$ 급 고강도강 다충 용접금속의 저온 충격인성에 미치는 미세조직의 영향
}

\author{
강 용 준,*๋이 창 희 ${ }^{* *}$ \\ *한국재료연구원 접합기술연구실 \\ **한양대학교 신소재공학부
}

\section{Effect of Microstructure on Low-Temperature Impact Toughness of Multi-Pass Weld Metal of 1 GPa Class High Strength Steel}

\author{
Yongjoon Kang*, and Changhee Lee** \\ *Joining Technology Department, Korea Institute of Materials Science, Changwon, 51508, Korea \\ **Division of Materials Science and Engineering, Hanyang University, Seoul, 04763, Korea
}

†Corresponding author: yjkang@kims.re.kr

(Received June 11, 2021; Revised June 21, 2021; Accepted June 22, 2021)

\begin{abstract}
A $1 \mathrm{GPa}$ class weld metal was prepared by multi-pass welding using a prototype flux-cored wire, and the correlation between microstructure and low-temperature impact toughness of the weld metal was investigated. The microstructure of the as-deposited columnar region and the equiaxed region reheated by subsequent welding passes was observed, and it was found that low-temperature transformation products such as bainite and martensite mainly developed in both regions. Since the prior austenite grains were coarse in the columnar region, the effective grain size of the final microstructure could be large; in this case, it was confirmed that the low-temperature impact toughness of the weld metal was very low. However, in the weld metal used in this study, acicular ferrite was formed inside the grains of the columnar region; the effective grain size and grain boundary misorientation distribution of the final microstructure were similar to those of the equiaxed region, and a good low-temperature impact toughness of the weld metal was obtained.
\end{abstract}

Key Words: High strength steel, Multi-pass weld metal, Acicular ferrite, Impact toughness

\section{1. 서 론}

해저와 극지방과 같은 극한환경에서의 지하자원 채굴 량이 증가함에 따라 높은 강도와 우수한 저온인성을 갖 는 해양구조물 및 라인파이프용 강재에 대한 수요가 증 가하고 있다. 최근에는 라인파이프용 API-X120, 해양 구조물용 $\mathrm{HY}-130$ 과 같은 $1 \mathrm{GPa}$ 급 고강도 강재가 개발되고 있다 ${ }^{1-3)}$. 이에 따라 $1 \mathrm{GPa}$ 급 강재의 맞춤 형 용접재료 개발을 위한 합금설계 연구가 꾸준히 수행 되고 있으나 ${ }^{4-6)}$, 아직까지 상용 제품의 생산은 이루어 지지 않은 실정이다.
결정립 미세화는 금속재료의 강도와 인성을 동시에 향 상시키는 가장 효과적인 방법이므로, 판재의 경우 제어 압연과 가속냉각을 통해 결정립을 미세화하여 고강도 및 고인성을 확보하는 것이 일반적이다 ${ }^{7)}$. 한편 용접금 속의 경우 제어압연과 같은 기술 적용이 불가능하고, 용융금속의 냉각에 따른 응고와 고상변태에 의해 최종 미세조직이 결정되므로 결정립을 미세화하기 위해서는 침상형 페라이트(acicular ferrite)의 분율을 높이는 것이 중요하다. 침상형 페라이트는 용접금속에 존재하 는 비금속개재물(non-metallic inclusion)로부터 핵 생성되어 사방으로 성장하기 때문에 결정립 크기를 감 소시키는 효과가 있는 것으로 잘 알려져 있다 ${ }^{8-10)}$. 그

Journal of Welding and Joining, Vol.39 No.3(2021) pp233-238

https://doi.org/10.5781/JWJ.2021.39.3.1 
러나 용접금속을 고강도화하기 위해 합금원소량을 증가 시키게 되면 경화능(hardenability)이 커지게 되어 침 상형 페라이트보다는 베이나이트(bainite), 마르텐사이 트(martensite)와 같은 미세조직의 발달이 우세해지 게 된다. 따라서 용접금속이 고강도화할수록 침상형 페 라이트 형성을 위한 구동력을 높이는 것이 중요하며, 이를 위해 침상형 페라이트 핵생성에 미치는 비금속개 재물의 역할을 명확히 규명하기 위한 연구가 꾸준히 수 행되고 있다 6 ,10-12).

최근 용착 그대로 상태의 단층(single-pass) 용접금 속과 Gleeble에 의해 재현된 재가열 용접금속에서의 미세조직 분석과 충격인성에 대한 평가가 이루어진 바 있다 ${ }^{13)}$. 그러나 현재까지 다층(multi-pass) 실용접부 를 대상으로 한 미세조직과 기계적 특성에 관한 연구는 미흡한 실정이다. 본 연구에서는 시험용 플럭스 코어드 와이어(flux cored wire)를 이용하여 다층용접한 인장 강도 $1 \mathrm{GPa}$ 급 용접금속의 미세조직을 분석하고 충격 인성과의 상관관계를 고찰하였다. 다층 용접금속에서 나 타나는 용착 그대로 상태의 주상정 영역(columnar zone) 과 후속패스에 의해 재가열된 등축정 영역(equiaxed zone)에서의 미세조직을 분석하였다. 침상형 페라이트 형성에 따라 주상정 영역의 유효결정립도가 감소하고 고경각입계 분율이 증가하게 되어 양호한 저온 충격인 성이 확보되는 것을 확인하였다.

\section{2. 실험 방법}

$1 \mathrm{GPa}$ 급 고강도강 용접금속을 제작하기 위해 두께 $20 \mathrm{~mm}$ 의 AH36 강판을 개선각 $45^{\circ}$ 로 하여 사용하였고, 시험용 플럭스 코어드 와이어를 이용하여 약 $20 \mathrm{~kJ} / \mathrm{cm}$ 의 입열량으로 다층용접을 실시하였다. 보호가스는 $80 \%$ $\mathrm{Ar}+20 \% \mathrm{CO}_{2}$ 혼합가스를 사용하였고, $200^{\circ} \mathrm{C}$ 이상의 예열 및 층간온도를 유지하였으며, 용접후열처리는 실시하 지 않았다. 광학발광분석기(optical emission spectroscopy) 를 이용하여 분석한 용접금속의 화학조성을 Table 1 에 제시하였다.

비커스경도계를 이용하여 $300 \mathrm{~g}$ 의 하중으로 $0.5 \mathrm{~mm}$ 의 간격을 갖는 1769 개 지점의 경도를 측정하여 용접 금속 단면에서 $30 \mathrm{~mm} \times 14 \mathrm{~mm}$ 영역내의 경도 분포 를 확인하였으며, 인장시험기를 이용하여 용접금속의 인장특성을 평가하였다. 충격인성은 샤르피 충격시험기 를 이용하여 $-40^{\circ} \mathrm{C}$ 에서 3 회 측정 후 평균값을 구하였

Table 1 Chemical composition of the weld metal (wt $\%$ )

\begin{tabular}{|c|c|c|c|c|c|c|c|c|c|c|}
\hline $\mathrm{C}$ & $\mathrm{Si}$ & $\mathrm{Mn}$ & $\mathrm{Ni}$ & $\mathrm{Cr}$ & $\mathrm{Mo}$ & $\mathrm{P}$ & $\mathrm{S}$ & $\mathrm{Al}$ & $\mathrm{Ti}$ & $\mathrm{Fe}$ \\
\hline 0.081 & 0.56 & 2.26 & 2.59 & 1.06 & 0.57 & 0.014 & 0.007 & 0.022 & 0.008 & Bal. \\
\hline
\end{tabular}

다. 인장 및 충격시편은 ISO 15792에 따라 용접금속 의 중앙, 즉 두께의 $1 / 2$ 지점에서 채취하였다. 인장시 편의 경우 길이방향을 용접방향과 동일하게 하여 전용 착금속(all-weld-metal) 시편을 제작하였으며, 충격시 편은 길이방향이 용접방향과 수직이면서 노치를 용접금 속의 중앙에 위치하게 하였다.

용접금속의 미세조직 분석을 위해 광학현미경(optical microscopy, $\mathrm{OM}$ ), 주사전자현미경(scanning electron microscopy, SEM), 전자후방산란회절(electron backscattered diffraction, EBSD), 투과전자현미경(transmission electron microscopy, TEM)을 이용하였다. $\mathrm{OM}$ 및 $\mathrm{SEM}$ 관찰을 위한 시편은 기계적 연마 후 $2 \%$ nital 용액으로 에칭(etching)하였으며, EBSD 분석을 위한 시편은 $5 \%$ perchloric acid $+95 \%$ methanol 전해액을 사용하여 전해연마 하였다. 개재물 분석을 위해 $\mathrm{TEM}$, 제한시야회절(selected area electron diffraction, $\mathrm{SAED}$ ) 및 에너지분광분석기(energy dispersive spectroscopy, EDS)를 이용하였으며, TEM 분석을 위한 시편은 jet polisher를 이용하여 준비하였다.

\section{3. 실험 결과 및 고찰}

용접금속의 매크로사진과 경도 분포를 Fig. 1에, 인 장시험 결과를 Fig. 2에 제시하였다. 후속패스에 의한 템퍼링 효과로 인해 상대적으로 경도가 낮은 영역도 있

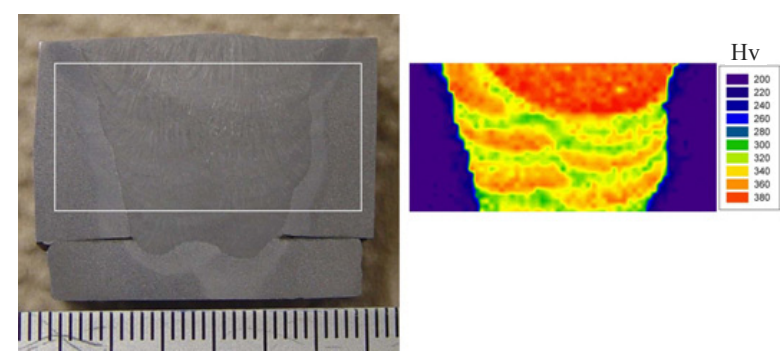

Fig. 1 Macrograph and hardness map of the weld metal

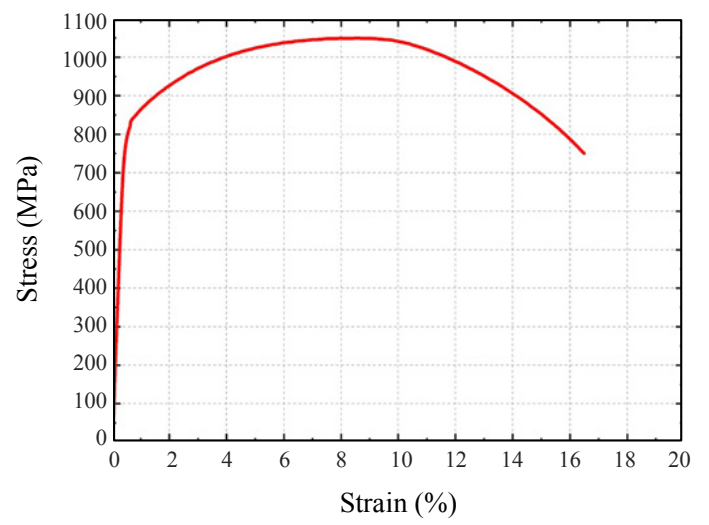

Fig. 2 Stress-strain curve of the weld metal 


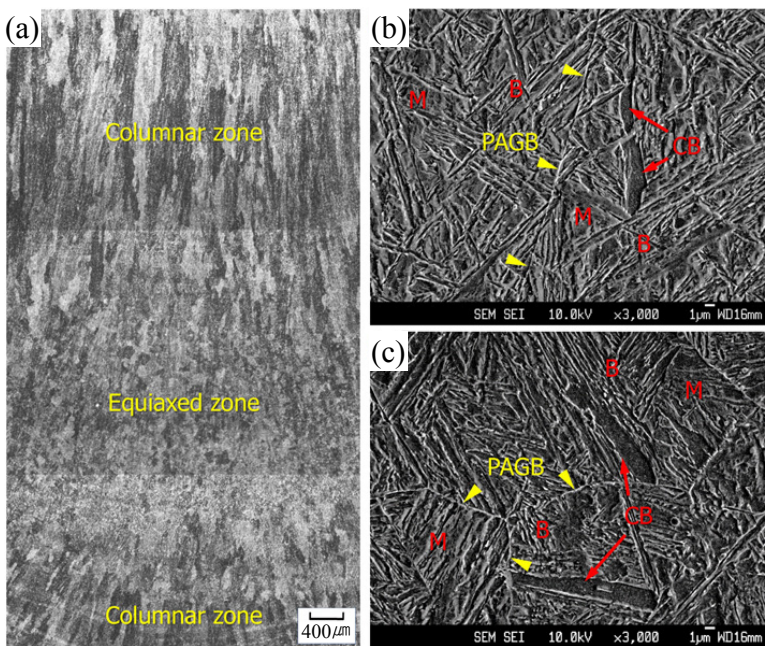

Fig. 3 (a) OM micrograph of the weld metal, (b, c) SEM micrographs of the columnar zone and equiaxed zone of the weld metal. B: bainite, M: martensite, CB: coalesced bainite, PAGB: prior austenite grain boundary

으나 대체로 $340 \mathrm{Hv}$ 이상의 매우 높은 경도를 나타내 며, $1050 \mathrm{MPa}$ 의 인장강도를 보이는 것으로 확인되었다.

Fig. 3은 $\mathrm{OM}$ 및 $\mathrm{SEM}$ 을 이용하여 관찰한 용착 그 대로 상태의 주상정 영역과 후속패스의 열영향에 의해 재결정된 등축정 영역의 미세조직을 나타낸 것이다. 두 영역 모두 대부분 베이나이트, 마르텐사이트와 같은 저 온변태 조직이 발달하였으며, coalesced 베이나이트 조직도 일부 관찰되었다. Coalesced 베이나이트 조직 은 상변태 구동력이 매우 클 때 방위차가 작은 인접한 래스들이 성장단계에서 유착(coalescence)됨으로써 형 성되기 때문에 상변태 온도가 낮은 $1 \mathrm{GPa}$ 급 고강도 강 용접금속에서 쉽게 나타나는 것으로 잘 알려져 있다 9,10,13-15). 한편, 주상정 영역은 일부 래스(lath)들이 서로 얽혀있는 구조를 가지는 반면, 등축정 영역의 경 우 인접한 래스들이 같은 방향으로 길게 성장하여 블록 (block) 및 패킷(packet)의 크기가 상대적으로 조대 하며 coalesced 베이나이트의 크기가 큰 것으로 관찰 되었다. 이것은 최근 연구9,10,13)에서 보고한 바 있듯이 등축정 영역과 달리 주상정 영역의 결정립 내부에서는 침상형 페라이트가 형성되어 래스들의 성장 및 유착을 방해하는 역할을 했기 때문인 것으로 판단된다. Fig. 4 에 나타낸 바와 같이 주상정 영역에서는 침상형 페라이 트가 개재물로부터 핵생성된 것을 쉽게 볼 수 있는 반 면, 등축정 영역에서는 거의 관찰되지 않았다.

Fig. 5는 TEM을 이용한 용접금속의 개재물 분석 결 과를 나타낸 것이다. 개재물은 결정상인 $\mathrm{MnS}, \mathrm{MnTi}_{2} \mathrm{O}_{4}$ 와 비정질상으로 구성된 것을 볼 수 있다. 최근 연구결 과에 따르면 개재물 표면에 위치한 $\mathrm{MnTi}_{2} \mathrm{O}_{4}$ 의 경우,

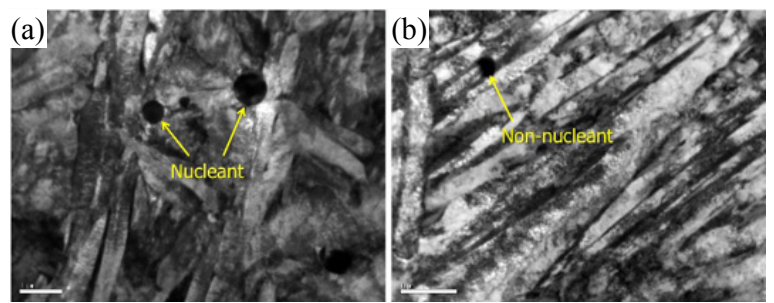

Fig. 4 TEM micrographs of the weld metal, (a) columnar zone, (b) equiaxed zone
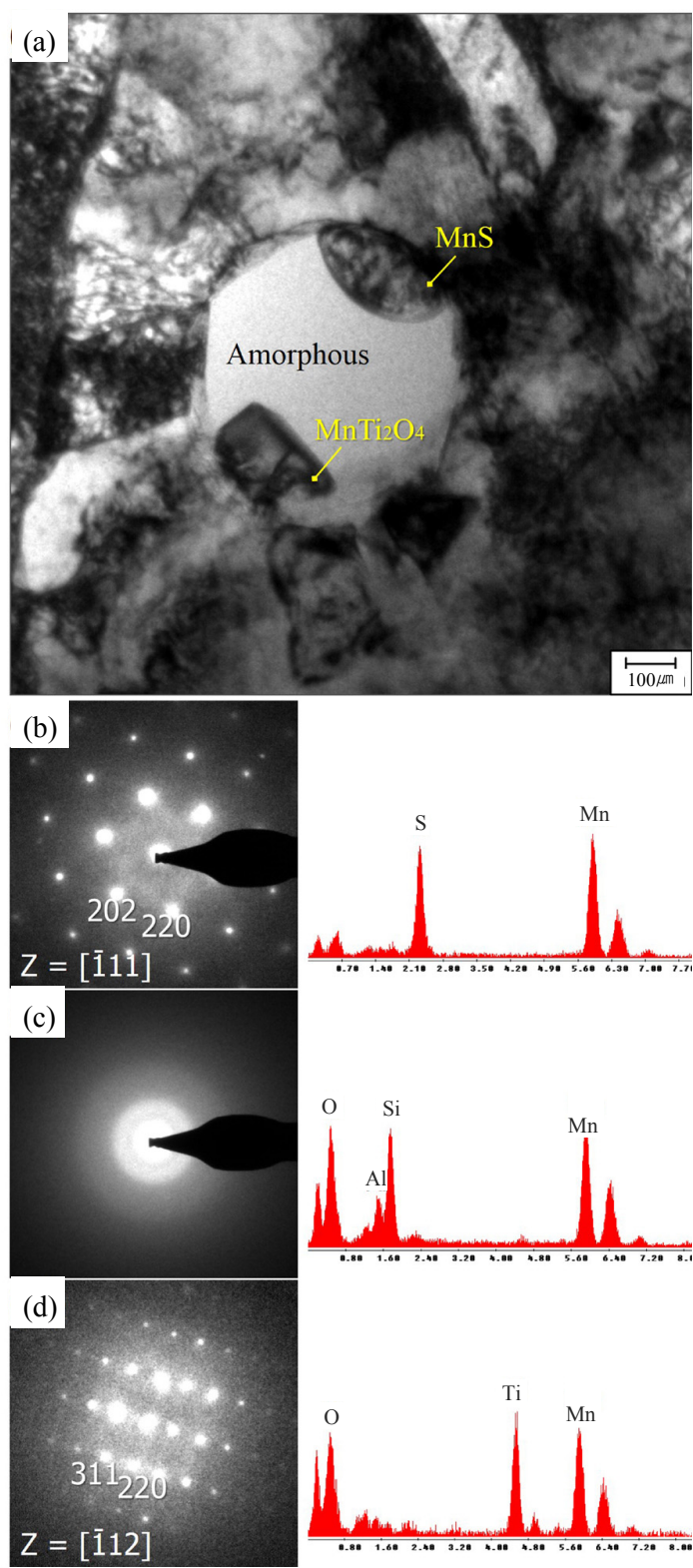

Fig. 5 The typical type of inclusions in the weld metal: (a) BF image, (b-d) SAED pattern and EDS of the $\mathrm{MnS}$, amorphous, and $\mathrm{Mn}^{\mathrm{Ti}_{2} \mathrm{O}_{4}}$

페라이트 래스와의 격자 정합성이 높은 동시에 주위에 용착 그대로 상태에서 $\mathrm{Mn}$-결핍층을 형성하므로 침상형 페라이트의 핵생성 능력이 높은 것을 알 수 있다 ${ }^{10,12)}$. 

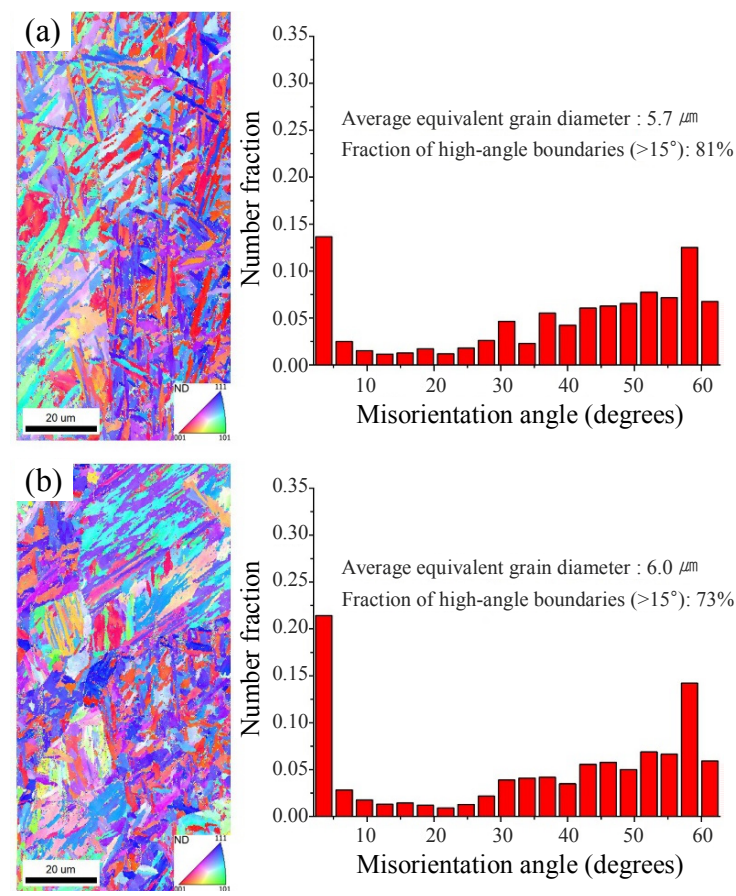

Fig. 6 Results of EBSD analysis of the weld metal, (a) columnar zone, (b) equiaxed zone

그러나 후속패스에 의해 재가열된 지역에서는 균질화에 의해 $\mathrm{Mn}$-결핍층이 사라지게 되어 개재물의 핵생성 능 력이 감소할 수 있으며, 이로 인해 등축정 영역에서 침 상형 페라이트가 발달하지 못한 것으로 사료된다.

Fig. 6은 $\mathrm{EBSD}$ 를 이용해 분석한 용접금속의 역극 점도(inverse pole figure) 및 결정립계 방위차 분포 를 나타낸 것이다. 주상정 영역에서는 결정립 내부의 개재물로부터 핵성된 침상형 페라이트에 의해 방향성 없이 비교적 무질서한 래스들이 주로 형성된 것을 관찰 할 수 있다. 반면 침상형 페라이트가 발달하지 못한 등 축정 영역에서는 인접한 래스들이 유사한 방위를 갖는 경우가 다수 관찰되었다. 평균 유효결정립도(effective grain size)는 주상정 영역에서 $5.7 \mu \mathrm{m}$, 등축정 영역 에서 $6.0 \mu \mathrm{m}$ 이며, $15^{\circ}$ 이상의 고경각입계 분율은 주상 정 영역과 등축정 영역에서 각각 $81 \%$ 와 $73 \%$ 으로 확 인되었다. 주상정 영역이 등축정 영역보다 prior 오스 테나이트 결정립 크기가 크지만, 최종 미세조직의 유효 결정립 크기와 고경각입계 분율이 유사하게 나타났으 며, 이는 고상변태 시 prior 오스테나이트 결정립 내부 에서 침상형 페라이트가 형성된 것이 주된 원인인 것으 로 판단된다.

침상형 페라이트의 형성이 주상정 영역의 유효결정립 도와 결정립계 방위차 분포에 미치는 영향을 확인하기 위 해 $\mathrm{Fe}-0.06 \mathrm{C}-0.31 \mathrm{Si}-1.7 \mathrm{Mn}-2.9 \mathrm{Ni}-0.33 \mathrm{Cr}-0.47 \mathrm{Mo}^{-}$ $0.17 \mathrm{Ti}$ 의 조성을 갖는 용접금속의 주상정 영역을 대상

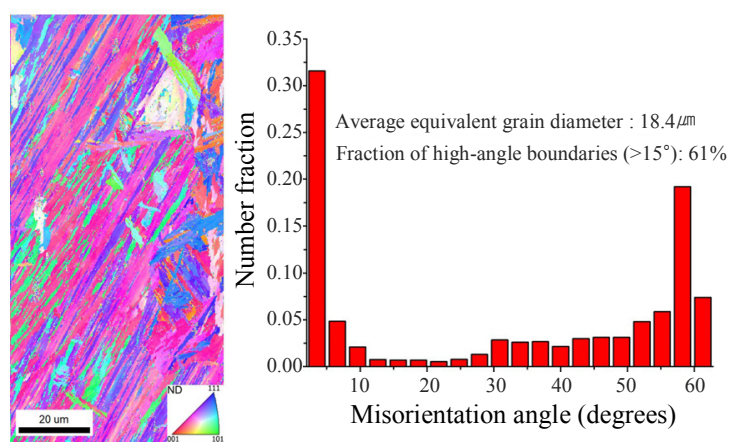

Fig. 7 Results of EBSD analysis of the columnar zone of the weld metal with a composition of $\mathrm{Fe}-0.06 \mathrm{C}$ 0.31 Si-1.7Mn-2.9Ni-0.33Cr-0.47Mo-0.17Ti (wt\%)

으로 $\mathrm{EBSD}$ 분석을 실시하였으며, 결과를 Fig. 7에 나타내었다. 해당 용접금속은 $977 \mathrm{MPa}$ 의 인장강도를 가지며, 낮은 침상형 페라이트 분율로 인해 $-40^{\circ} \mathrm{C}$ 에서 의 평균 충격에너지는 $10 \mathrm{~J}$ 로 매우 낮은 것으로 확인 된 바 있다 ${ }^{6)}$. Fig. 7 에서 보듯이 해당 용접금속은 평 균 유효결정립도가 $18.4 \mu \mathrm{m}$ 로 본 연구에서 사용한 용 접금속에 비해 매우 크게 나타났으며, 고경각입계 분율 은 $61 \%$ 이다. 즉 침상형 페라이트 조직의 유무에 따라 용접금속 주상정 영역의 유효 결정립도 및 결정립계 방 위차 분포가 크게 달라지는 것을 확인할 수 있다.

위에서 언급한 $\mathrm{Fe}-0.06 \mathrm{C}-0.31 \mathrm{Si}-1.7 \mathrm{Mn}-2.9 \mathrm{Ni}^{-}$ $0.33 \mathrm{Cr}-0.47 \mathrm{Mo}-0.17 \mathrm{Ti}$ 의 조성을 갖는 용접금속과 본 연구에서 사용한 $1 \mathrm{GPa}$ 급 용접금속의 $-40^{\circ} \mathrm{C}$ 에서 평 균 충격에너지를 비교하여 Fig. 8에 나타내었다. 합금 원소량의 증가로 인해 본 연구에서 사용한 용접금속이 인장강도가 더 높음에도 불구하고 평균 충격에너지는 $52 \mathrm{~J}$ 로 양호한 것으로 확인되었다. 여러 연구를 통해 유효결정립도가 작고 고경각입계 분율이 높을수록 균열 전파를 효과적으로 방해하게 되어 저온 충격인성이 증 가하는 것으로 알려져 있다 ${ }^{1,2,16)}$. 본 연구에서 분석한

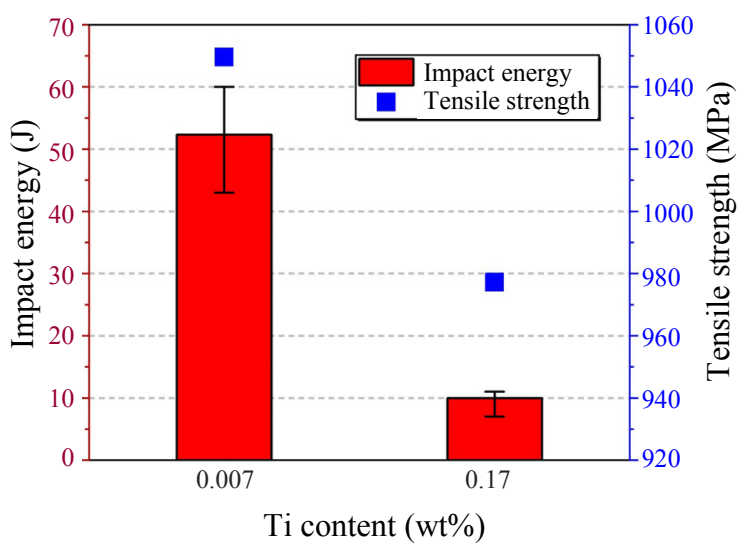

Fig. 8 Comparison of the mechanical properties of the weld metals with different alloy contents 
다층 용접금속이 $1 \mathrm{GPa}$ 를 상회하는 높은 강도를 가짐 에도 불구하고 양호한 저온 충격인성을 가지는 것은 주 상정 영역에서 침상형 페라이트가 형성됨으로 인해 최 종 미세조직의 유효결정립 크기가 감소하고 고경각입계 분율이 증가하였기 때문인 것으로 판단된다.

\section{4. 결 론}

본 연구에서는 시험용 플럭스 코어드 와이어를 이용 하여 다층용접한 인장강도 $1 \mathrm{GPa}$ 급 용접금속의 미세 조직을 분석하고 저온 충격인성과의 상관관계를 분석하 였다. 용착 그대로 상태의 주상정 영역과 후속패스의 열 영향에 의해 재결정된 등축정 영역의 미세조직을 관찰 한 결과 두 영역 모두에서 베이나이트, 마르텐사이트와 같은 저온변태 조직이 발달한 것을 확인하였다. 주상정 영역은 prior 오스테나이트 결정립이 조대하므로 최종 미세조직의 유효결정립도가 크게 나타날 수 있는데, 이 경우 다층 용접금속의 저온 충격인성은 매우 낮은 것으 로 확인되었다. 그러나 본 연구에서 사용한 다층 용접 금속의 경우 주상정 영역의 prior 오스테나이트 결정립 내부에서 침상형 페라이트가 형성되어 최종 미세조직의 유효결정립 크기와 결정립계 방위차 분포가 등축정 영 역과 유사한 수준으로 나타났으며, 이를 통해 $1 \mathrm{GPa}$ 를 상회하는 높은 강도를 가짐에도 불구하고 양호한 저온 충격인성을 보이는 것으로 판단된다.$$
\text { 후기 }
$$

이 논문은 2021년도 정부(산업통상자원부)의 재원으 로 한국에너지기술평가원의 지원을 받아 수행된 연구임 (No. 20206510100030)

ORCID: Yongjoon Kang: http://orcid.org/0000-0001-7088-9384 ORCID: Changhee Lee: http://orcid.org/0000-0002-1775-3020

\section{References}

1. S. Y. Han, S. Y. Shin, S. Lee, J. Bae, and K. Kim, Effect of cooling conditions on microstructures and mechanical properties in API X80 linepipe steels, J. Korean Inst. Met. Mater. 47(9) (2009) 523-532.

2. H. K. Sung, S. Y. Han, B. Hwang, C. G. Lee, N. J. Kim, and S. Lee, Tensile and Charpy impact properties of high-strength bainitic steels fabricated by controlled rolling process, Korean J. Met. Mater. 48(7) (2010) 615-624.

3. W. H. Song, D. H. Seo, and J. Y. Yoo, Development trend of linepipe steel and it's weldability, J. Korean Weld. Join. Soc. 27(1) (2009) 34-48.
4. E. Surian, J. Trotti, A. Cassanelli, and L. A. De Vedia, Influence of chromium on the mechanical properties and microstructure of weld metal from a high-strength SMA electrode, Weld. J. 73 (1994) 45s-53s.

5. Y. Kang, J. Jang, S. Park, and C. Lee, Influence of Ni on the microstructure and mechanical properties of HSLA steel welds, J. Korean Weld. Join. Soc. 30(4) (2012) 339-344.

https://doi.org/10.5781/KWJS.2012.30.4.339

6. Y. Kang, J. Jang, J. H. Park, and C. Lee, Influence of Ti on non-metallic inclusion formation and acicular ferrite nucleation in high-strength low-alloy steel weld metals, Met. Mater. Int. 20(1) (2014) 119-127. https://doi.org/10.1007/s12540-014-1013-1

7. Y. W. Kim, J. H. Kim, S. G. Hong, and C. S. Lee, Effects of rolling temperature on the microstructure and mechanical properties of Ti-Mo microalloyed hot-rolled high strength steel, Mat. Sci. Eng. A-Struct. 605 (2014) 244-252. https://doi.org/10.1016/j.msea.2014.03.054

8. M. Fattahi, N. Nabhani, E. Rafiee, M. Nasibi, E. Ahmadi, and Y. Fattahi, Effect of Ti-based inclusions and acicular ferrite on the corrosion performance of multipass weld metals, Mater. Chem. Phys. 146 (2014) 105-112. https://doi.org/10.1016/j.matchemphys.2014.03.006

9. Y. Kang, G. Park, S. Jeong, and C. Lee, Correlation between microstructure and low-temperature impact toughness of simulated reheated zones in the multi-pass weld metal of high-strength steel, Metall. Mater. Trans. A, 49A (2018) 177-186. https://doi.org/10.1007/s11661-017-4384-3

10. Y. Kang and C. Lee, Nucleation behavior of acicular ferrite in $1 \mathrm{GPa}$ class high strength steel weld metal, $J$. Weld. Join. 37(1) (2019) 21-26. https://doi.org/10.5781/JWJ.2019.37.1.3

11. H. J. Kim and B.Y. Kang, Role of non-metallic inclusions on the nucleation of acicular ferrite, $J$. Korean Weld. Join. Soc. 18(6) (2000) 25-32.

12. Y. Kang, S. Jeong, J. H. Kang, and C. Lee, Factors affecting the inclusion potency for acicular ferrite nucleation in high-strength steel welds, Metall. Mater. Trans. A, 47A (2016) 2842-2854. https://doi.org/10.1007/s11661-016-3456-0

13. Y. Kang, G. Park, S. Jeong, and C. Lee, Microstructure and mechanical properties of reheated zones in the multi-pass weld metal of high-strength steel, J. Weld. Join. 35(6) (2017) 21-26. https://doi.org/10.5781/JWJ.2017.35.6.4

14. E. Keehan, L. Karlsson, H. K. D. H. Bhadeshia, and M. Thuvander, Three-dimensional analysis of coalesced bainite using focused ion beam tomography, Mater. Charact. 59 (2008) 877-882. https://doi.org/10.1016/j.matchar.2007.07.011 
15. K. Brunelli, P. Bassani, N. Lecis, L. Peruzzo, C. Maranzana, and M. Dabalà, Microstructural evolution of a continuously cooled air hardening steel, Metallogr. Microstruct. Anal. 2 (2013) 56-66.

https://doi.org/10.1007/s13632-013-0062-z
16. B. Hwang, Y. G. Kim, S. Lee, Y. M. Kim, N. J. Kim, and J. Y. Yoo, Effective grain size and Charpy impact properties of high-toughness X70 pipeline steels, Metall. Mater. Trans. A, 36A (2005) 2107-2114. https://doi.org/10.1007/s11661-005-0331-9 